Adsorption behavior of Ni-doped $\mathrm{ZnO}$ monolayer upon $\mathrm{SF}_{6}$ decomposed components and effect of applied electric field

\title{
Min Liu*
}

Chongqing Industry Polytechnic College, Chongqing 401120, China

Supporting Information

Table S1 Total energy of Ni-ZnO monolayer with varying k-point

\begin{tabular}{cccccc}
\hline k-point & $4 \times 4 \times 1$ & $5 \times 5 \times 1$ & $6 \times 6 \times 1$ & $7 \times 7 \times 1$ & $8 \times 8 \times 1$ \\
\hline Total energy (Ha) & -5467.682554 & -5467.682554 & -5467.682554 & -5467.682554 & -5467.682554 \\
\hline
\end{tabular}

